GEOLOGICAL SURVEY CIRCULAR 748

\title{
A Device for Automatic Photoelectric Control of the Analytical Gap for Emission Spectrographs
}




\section{A Device for Automatic Photoelectric Control of the Analytical Gap for Emission Spectrographs}

By John A. Dietrich, Elmo F. Cooley, and Kenneth J. Curry

GEOLOGICAL SURVEY CIRCULAR 748 
United States Department of the Interior

THOMAS S. KLEPPE, Secretary

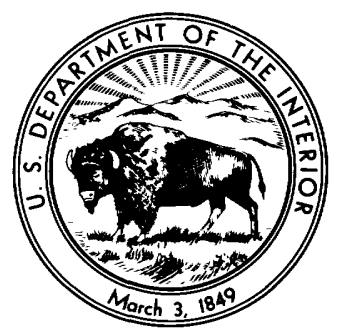

Geological Survey

V. E. McKelvey, Director 


\section{CONTENTS}

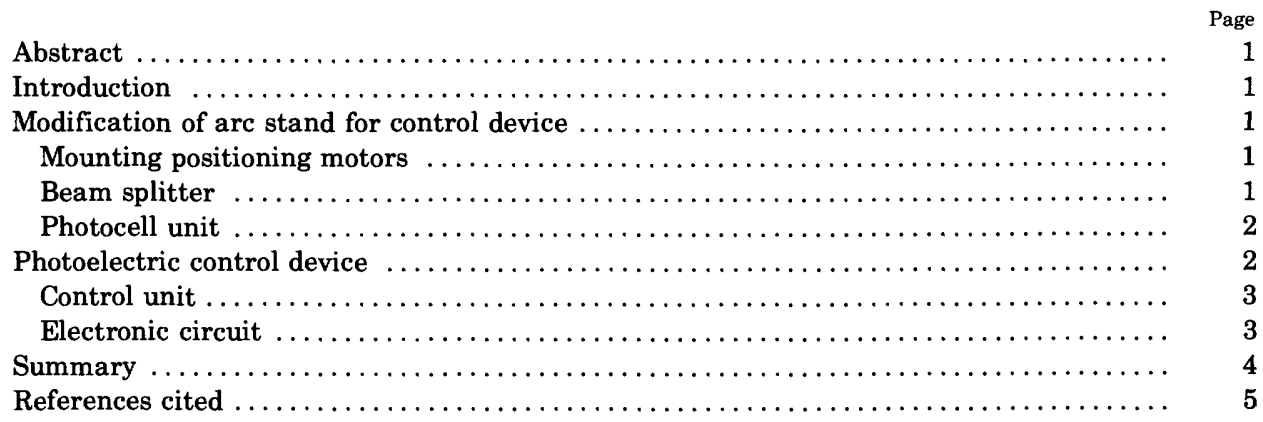

\section{ILLUSTRATIONS}

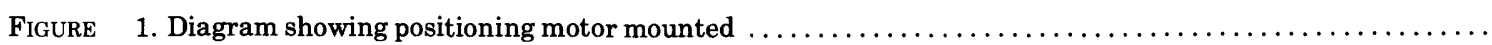

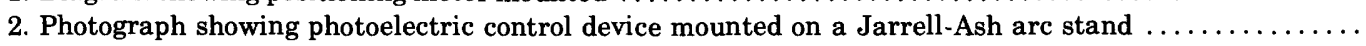

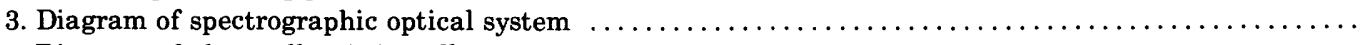

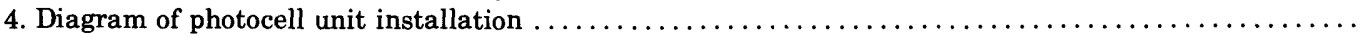

5. Schematic diagram of the electronic circuit

TABLE

TABLE 1. Electronic parts list 


\title{
A Device for Automatic Photoelectric Control of the Analytical Gap for Emission Spectrographs
}

\author{
By John A. Dietrich, Elmo F. Cooley, and Kenneth J. Curry \\ ABSTRACT

\section{MODIFICATION OF ARC STAND FOR CONTROL DEVICE}

A photoelectric device has been built that automatically controls the analytical gap between electrodes during excitation period. The control device allows for precise control of the analytical gap during the arcing process of samples, resulting in better precision of analysis.

\section{INTRODUCTION}

Of the many factors that contribute to errors in spectrographic analysis, one is variation in the spacing of electrodes during the period of excitation. During excitation, part of each electrode is continuously burning away. In order to maintain a constant analytical gap, the operator must manually control the electrode spacing, a task which demands the operator's full attention. The total-energy method used by the U.S. Geological Survey for spectrographic analysis of geologic materials (Grimes and Marranzino, 1968) requires a burn time of 140 seconds for each sample. A photoelectric control maintains the correct gap spacing during this arcing of the sample.

A method for photoelectric control of the analytical gap has been described by J. D. Caylor (1967). Our technique differs from Caylor's primarily in that our device units are designed for installation on commercial arc stands with only minor modification of the stands. Our purpose was to devise a system that could be easily installed in the U.S. Geological Survey mobile spectrographic laboratories (Canney and others, 1957; and Arcs and Sparks, 1967), which provide rapid, on-thespot analyses for geologists in the field.

This paper describes the apparatus and its installation in a Jarrell-Ash Model 19-300 arc stand.

\section{MOUNTING POSITIONING MOTORS}

The two positioning motors (M1 of table 1) may be mounted on the control rods in the front or back of the arc stand. In either case, the two motors' frames are attached to an aluminum plate to prevent their turning during operation. To mount the motors in the back of the arc stand, it is necessary to extend the horizontal control rods through the back of the arc stand (fig. 1). Onequarter-inch-diameter holes are drilled in the back panel and the support frame on line with the existing horizontal control rods. The extension rods are coupled to the existing horizontal control rods and to the positioning motors by steel sleeves which are fitted with set screws. A brass bushing is fastened to the support frame of the arc stand to give the extension rods added support and stability.

For front mounting of the positioning motors, no alterations are required other than replacing the control knobs with the positioning motors (fig. 2).

\section{BEAM SPLITTER}

The beam splitter is made by sandwiching a strip of solar reflective film between two 1- by 3inch glass microscope slides. To project the electrode images onto the photocells, which are mounted in the photocell holder, the beam splitter is placed inside the arc stand near the front, perpendicular to the photocells, and bisecting the optical path between the back mirror and projection screen (fig. 3). A 21/2-inch-diameter hole is cut in the side of the arc stand to allow projection of the 


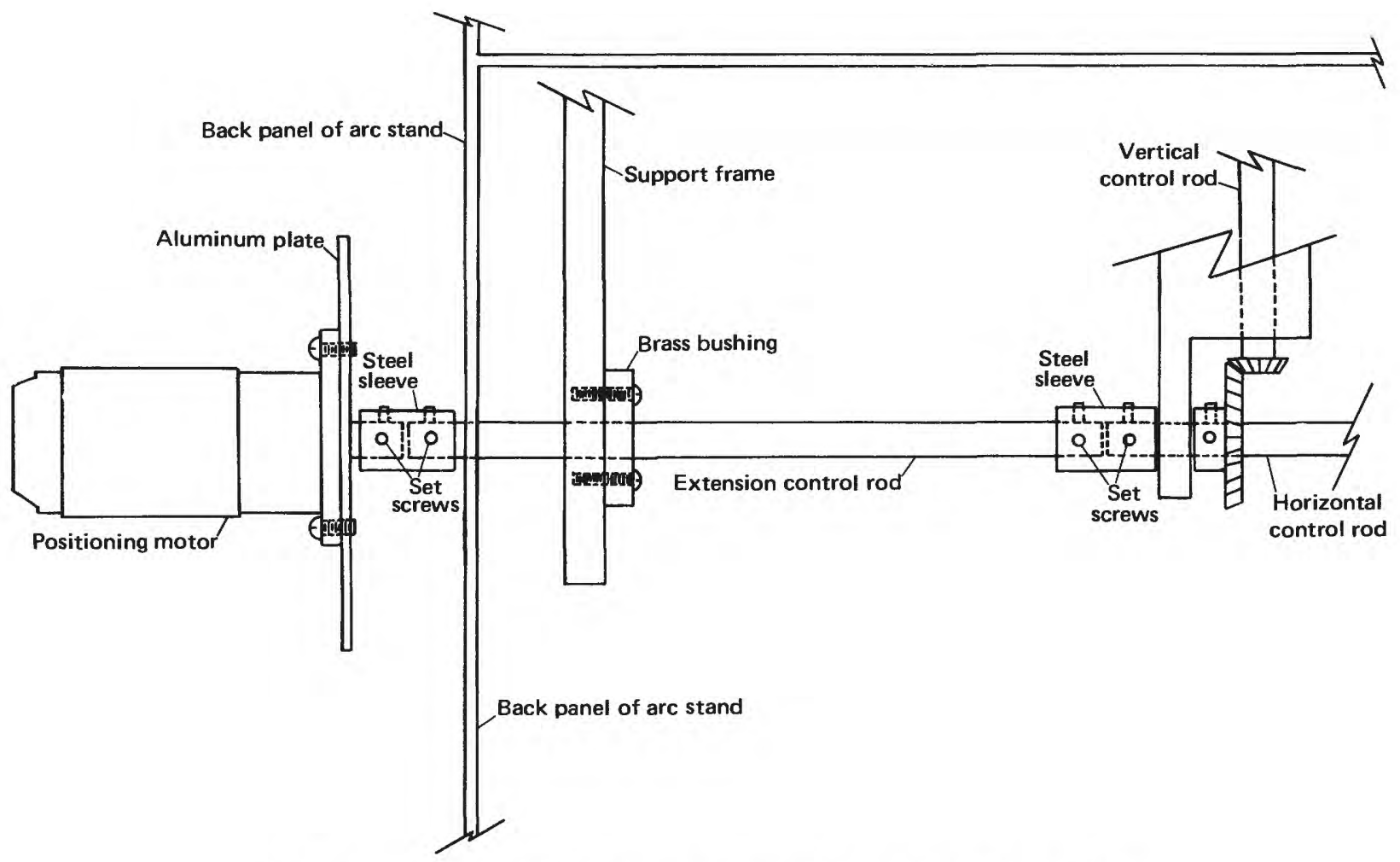

FIGURE 1.- One of the positioning motors mounted on the back of the arc stand.

electrode images from the beam splitter to the photocells (fig. 4).

\section{PHOTOCELL UNIT}

The photocell holder (fig. 4) is made from micarta (laminated plastic). The dimensions of the holder are $3^{1 / 4}$ by $1^{1 / 2}$ by $1^{1 / 4}$ inch. Four $31 / 64$-inchdiameter holes are drilled side-by-side in a row in the holder to house the photocells. A 3/16-inchwide adjustment slot is cut in one end of the photocell holder to allow for minor vertical adjustments to correctly position the photocell unit. With the electrodes in proper positions, the holder is placed so that each electrode image fully covers one hole plus approximately half of an adjacent hole. The photocells are masked by a piece of cardboard attached to the inside of the photocell holder between the beam splitter and the photocells. A 1/8inch-wide slit is cut in the cardboard the length of the four photocells and is covered with a blue acrylic plastic filter. The mask and filter prevent the cells from being affected by stray light and have a damping effect on the response of the electronic circuit.

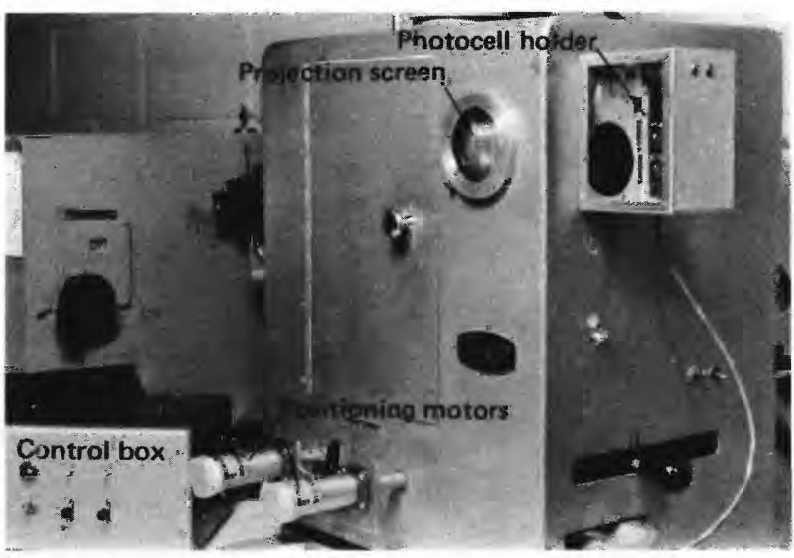

FIGURE 2.- Photoelectric control device mounted on the front of a Jarrell-Ash arc stand.

\section{PHOTOELECTRIC CONTROL DEVICE}

The photoelectric control device consists of a control box, two positioning motors, and four photocells mounted in their holder (fig. 2). The control box houses the power supply, electronic circuit (fig. 5), and control panels. The switches for operating the positioning motors are located on 


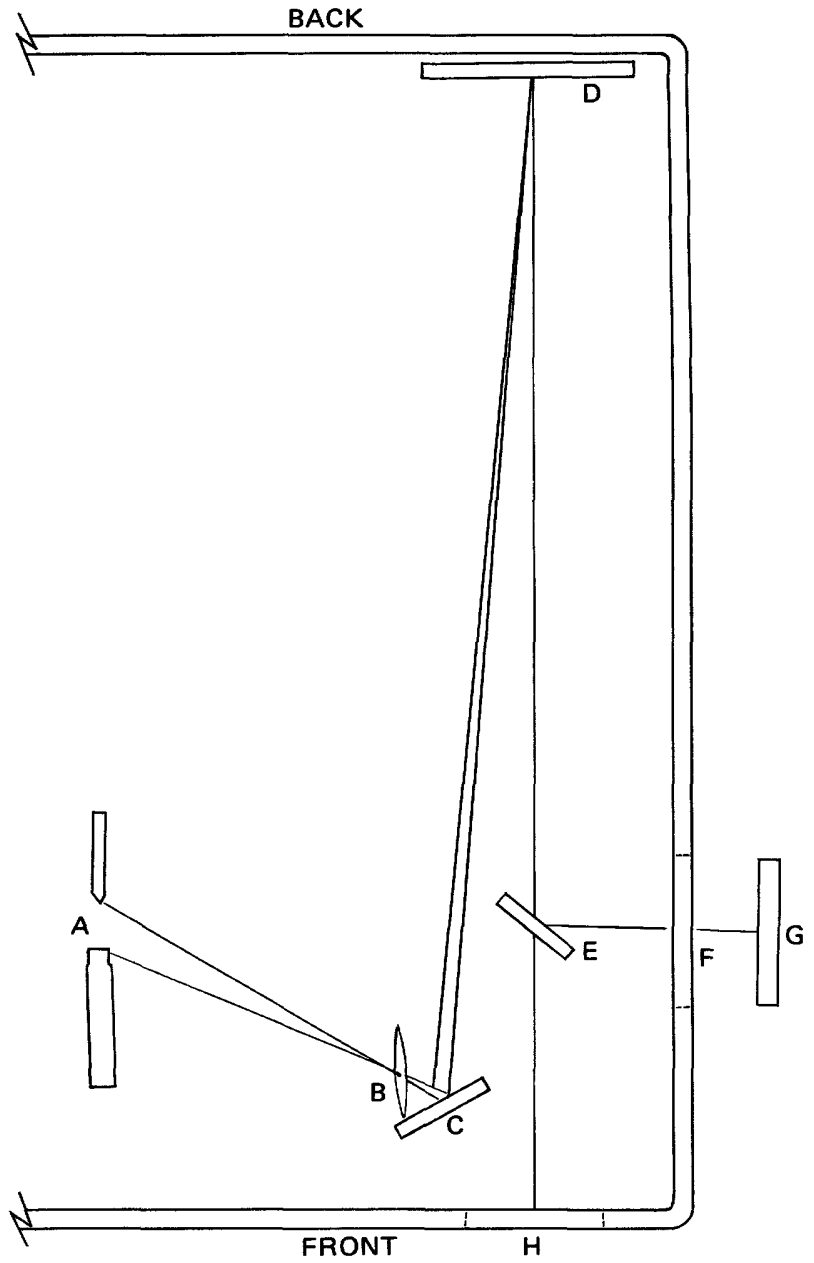

FIGURE 3. - Spectrograph optical system showing illumination path of the electrodes: A) electrodes; B) lens; C) front mirror; D) back mirror; E) beam splitter; F) opening in side of arc stand; G) photocell unit; $\mathrm{H}$ ) projection screen.

the front control panel. Controls for the potentiometers in the bridge circuits are located on the back control panel. Electrical connections for the motors and photocells are also on the back control panel.

\section{CONTROL UNIT}

A three-position toggle switch, located on the front control panel, allows the controls to be operated manually or set for automatic control. The manual controls are used for loading, unloading, and positioning the electrodes. The electrode tips can be positioned at the desired arc gap by adjusting the potentiometers in the bridge circuits. Readjustment of the potentiometers is required only occasionally.

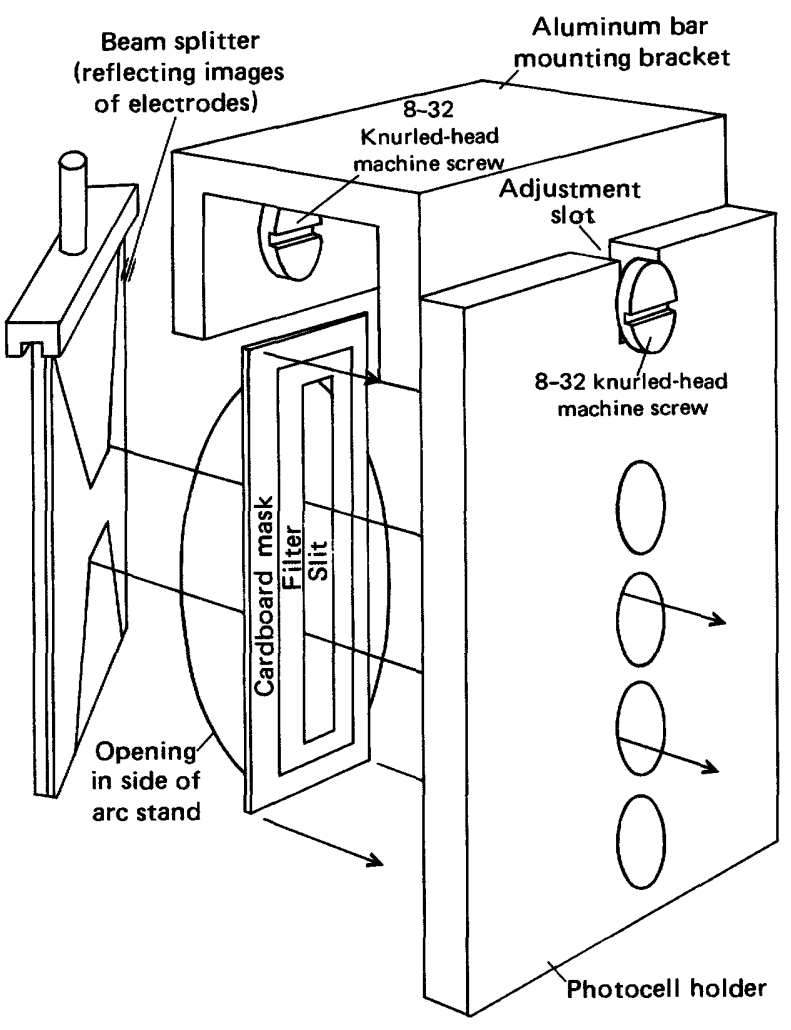

Figure 4.- Installation setup of photocell unit on the side of the arc stand.

To begin the arcing procedure, the images of the two electrodes are approximately positioned manually, and then the controls are set on automatic. Each electrode is controlled by its own electronic circuit. Only the action and control of one electrode will be described. During arcing of the sample, the electrode's tip is burned away, causing a lessening of the luminous image on one of the photocells. When one of the cells receives less light than the other cell receives, an output voltage is produced from the differential amplifier. This output voltage is connected to a power amplifier where the signal is amplified to drive a positioning motor mounted on the electrode control rod. The motor drives the control rod in the direction that will produce a balance in the bridge circuit and thereby maintain constant electrode spacing during the sample burning time.

\section{ELECTRONIC CIRCUIT}

The electronic circuit is a DC servo control amplifier. A diagram of the circuit is shown in figure 5 and a corresponding list of electronic 
parts is given in table 1 . The two electrodes have identical control circuits. The power supply is used for both circuits. Only one circuit will be described and illustrated.

Two photocells (one pair) are mounted in the image of one electrode. The pairs of photocells are

TABLE 1. - Electronics parts list

\begin{tabular}{|c|c|c|}
\hline Number & Item & Description \\
\hline R1 & Resistor . . . . . . & $2,200 \mathrm{ohms}, 1 / 8$ watt \\
\hline R2 & Potentiometer .... & $5,000 \mathrm{ohms}$ \\
\hline R3 & $\begin{array}{l}\text { Potentiometer, } \\
\text { miniature. }\end{array}$ & $10,000 \mathrm{ohms}$ \\
\hline $\mathrm{R} 4,5$ & Resistors ...... & $10,000 \mathrm{ohms}, 1 / 8$ watt. \\
\hline $\mathrm{PC} 1,2$ & Photoconductive cells & GE type B425 \\
\hline IC1 & Operational amplifier & Fairchild type UA741HC \\
\hline Q1 & Transistor ......... & GE $044 C 8$ \\
\hline Q2 & Transistor . . . . . . . . & GE $045 C 8$ \\
\hline $\mathrm{S} 1$ & Switch $\ldots . \ldots \ldots$ & $\begin{array}{l}\text { GC Electronics No. } \\
\quad 35-728\end{array}$ \\
\hline S2 & Switch ........ & SPST \\
\hline M1 & Gear motor...$\ldots$ & $\begin{array}{c}\text { Globe Motors No. } \\
\text { 319A126-2 }\end{array}$ \\
\hline D1, 2 & $\begin{array}{l}\text { Zener diode } \ldots \ldots \\
\text { Power supply } \ldots \ldots\end{array}$ & $\begin{array}{l}15 \mathrm{~V} 10 \mathrm{~W} \\
\text { Power One Model } \\
\text { HAA15-8 }\end{array}$ \\
\hline
\end{tabular}

connected into opposite legs of a balanced bridge amplifier. A garden-variety, internally compensated, operational amplifier receives the signal from the bridge amplifier and provides a high-gain voltage output proportional to the small difference voltage created by any imbalance in the bridge. The signal from the operational amplifier is fed to a pole-sensitive power amplifier which drives the electrode positioning motor. This causes the motor to drive the electrode and its image in the direction required to cancel the difference in voltage seen across the input of the operational amplifier. Two diodes connected back-to-back across the motor protect the transistors from back EMF induced by the motor. A toggle switch enables manual operation of the motor drive. Power requirements of the system are plus and minus 15 volts at 15 watts.

\section{SUMMARY}

The automatic gap control device described in this paper is simple and relatively inexpensive. Most arc stands can easily be modified to permit its installation. The device is needed by operators employing long-burn-time methods of

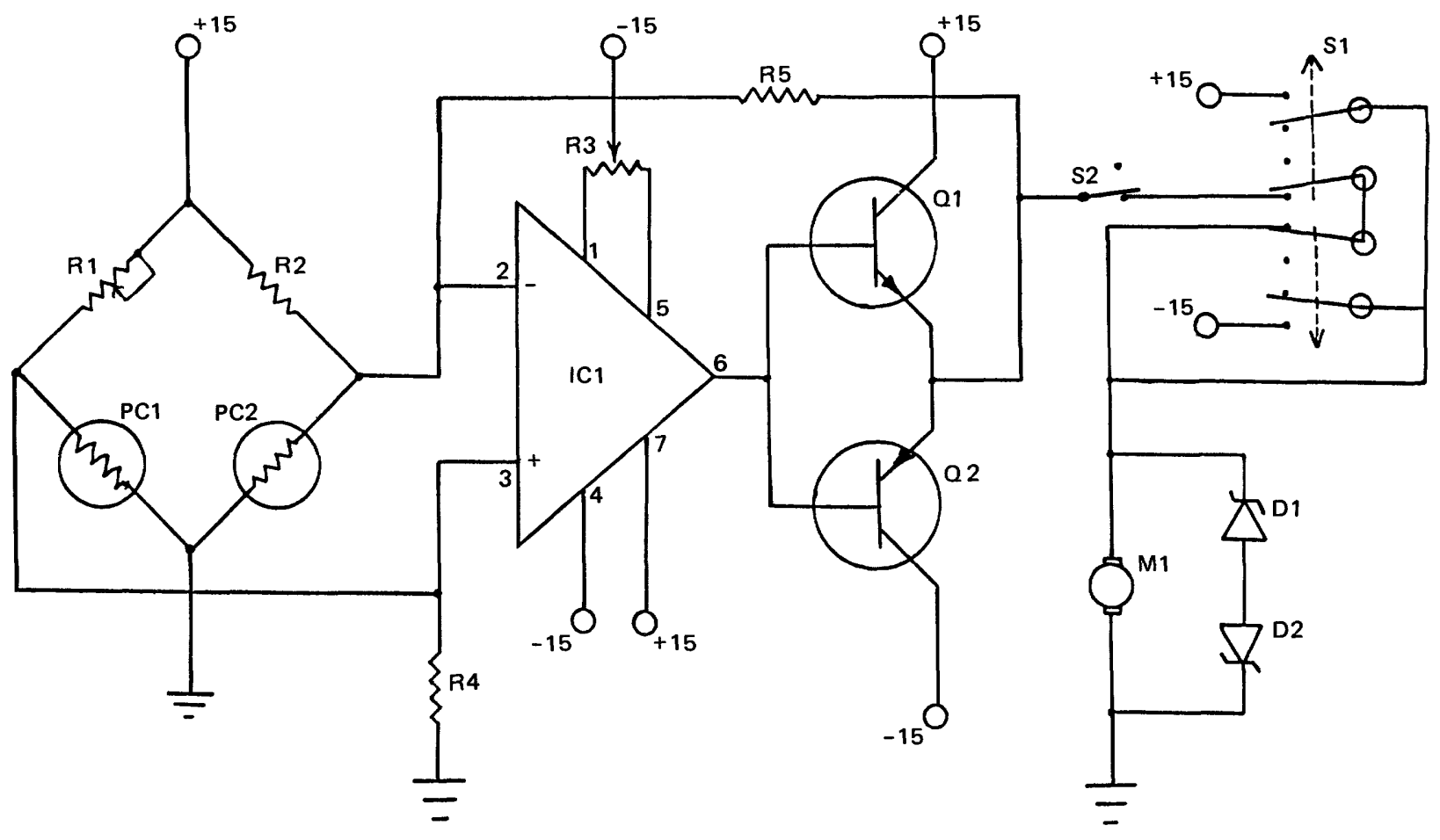

FIGURE 5.-Schematic diagram of the electronic circuit. 
spectrographic analysis because it standardizes the arcing process and allows for precise control of the analytical gap between electrodes during arcing.

When using the total-energy method requiring a long burn time, as employed by the U.S. Geological Survey, the operator can prepare other samples for analysis during the arcing process. This allows for a 25 to 30 percent increase in the volume of spectrographic analyses. The device has been successfully used for over a year on both a Jarrell-Ash and an ARL arc stand.

\section{REFERENCES CITED}

Arcs and Sparks, 1967, United States Geological Survey lab on wheels: Ultra Carbon Corp., Arcs and Sparks, v. 12, no. 2, p. 3-5.

Canney, F. C., Myers, A. T., and Ward, F. N., 1957, A truckmounted spectrographic laboratory for use in geochemical exploration: Econ. Geology, v. 52, no. 3, p. 289-306.

Caylor, J. D., 1967, An automatic electrode loader and positioner for emission spectrographs: Union Carbide Corp. Y-12 Plant, Oak Ridge, Tenn., Report Y-1569, 12 p.

Grimes, D. J., and Marranzino, A. P., 1968, Direct-current arc and alternating-current spark emission spectrographic field methods for the semiquantitative analysis of geologic materials: U.S. Geol. Survey Circ. 591, 6 p. 